Maraschin, C.

"Pesquisar e intervir"

\title{
PESQUISAR E INTERVIR
}

\author{
Cleci Maraschin \\ Universidade Federal do Rio Grande do Sul
}

RESUMO: O texto busca, a partir de conceitos teóricos da Biologia do Conhecer, discutir a pesquisa-intervenção como uma ação que cria possibilidades de interconexão entre a pesquisa e a extensão no viver universitário. A condição de observador-dependente, produzido a partir de uma rede de conversações que constitui o domínio explicativo científico é tomada para compreender as possibilidades de exercício da função de autoria, bem como as implicações éticas decorrentes. Postula-se que a pesquisa-intervenção possa - ela mesma - constituir-se como inovação ao propor perspectivas metodológicas de ação capazes de sustentar trabalhos de intervenção para além da pesquisa propriamente dita.

PALAVRAS-CHAVE: pesquisa universitária, pesquisa intervenção, biologia do conhecer.

\section{TO RESEARCH AND TO INTERVENE}

ABSTRACT: This text discusses intervention-research as an action that creates possibilities of interconnections between research and extension in universitarian daily life from the basic theoretical concepts of Biology of Knowledge. Produced from a network of conversations which constitutes the explanatory scientific domain, the condition of dependent-observer is taken in order to understand the possibilities of exercising authorial function, as well as the resultant ethical implications. It's postulated that interventionresearch methodology can constitute itself as an inovation when proposing methodological perspectives of action capable of sustaining interventions that sustain themselves beyond the research in itself.

KEYWORDS: university research, intervention-research, biology of knowledge. 


\section{O PESQUISAR E A UNIVERSIDADE}

Apesar da cara formulação de "indissociabilidade entre ensino-pesquisa-extensão" que distingue a universidade de outras instituições sociais ao implicar-se simultaneamente com a formação, com a produção e a difusão de conhecimentos, a experiência universitária é atravessada por várias dicotomias. Essas dicotomias podem ser vividas no momento em que percursos profissionais são separados dos acadêmicos; em que disciplinas teóricas tornam-se pré-requisitos para disciplinas práticas; quando a pesquisa denominada de básica é investida de valor diferenciado da denominada pesquisa aplicada; ou ainda, no fortalecimento das especialidades que são distinguidas quase que exclusivamente pelos modos de resolução de problemas em um campo específico de atuação e não por uma problematização metodológico-conceitual capaz de as transversalizar. Essas dicotomias se atualizam em diferentes práticas institucionais, constituem modos de pensar que têm efeitos de realidade ao sustentar a produção dos currículos, ao organizar maneiras de encadear conceitos, ao modelar perfis de egressos, ao propor modos de avaliar produtos e processos universitários e profissionais, potencializando investimentos e valorização de algumas atividades em detrimento de outras. Ao final, não escapamos da classificação hierárquica e produtivista que predomina em relação à criação e à disseminação do conhecimento, que pode levar a uma desvalorização da pesquisaintervenção muitas vezes considerada como extensão universitária.

A intenção deste texto é fazer alguns apontamentos para refletir sobre o pesquisar como criação de laços entre o ensino e a extensão. Interessa discutir a atividade de pesquisa como potência instituinte, ou seja, virtualmente capaz de desestabilizar modos de ação já recorrentes na instituição. Como criação de territórios de conhecimentos-subjetividades que põem em movimento, no mesmo ato, conhecimento, intervenção e autoria. No momento em que tomamos o pesquisar como uma ação de conhecimento, criação de territórios de subjetivação, como indica o título deste texto, é possível propor que seus efeitos podem ser pensados para além dos limi- 
Maraschin, C

"Pesquisar e intervir"

tes da pesquisa em seu sentido estrito. Deseja-se pensar os modos através dos quais a atividade da pesquisa pode ativar outras formas de participação em uma vida acadêmica e profissional que aposta nos multiversos sentidos e nas singularidades autorais.

Para seguir esse intento reflexivo, faremos um breve percurso em alguns conceitos-ferramentas da Biologia do Conhecer, no intuito de pensar o pesquisar em uma ecologia universitária configurada como redes de conversação e de convivência entre pares que sustentam múltiplos domínios de conhecimento.

\section{PESQUISAR COMO UM DOMÍNIO DE CONVIVER}

Uma primeira reflexão que proponho é explicitar a razão pela qual para pensar o pesquisar no contexto universitário e, mais proximamente, no contexto da Psicologia, recorro a uma conversa teórica com a Biologia. O diálogo entre Psicologia e Biologia tem já uma tradição e continua produzindo distintos modos explicativos para pensar as relaçóes entre o que é comumente classificado como correspondente à ordem do "mental", daquilo que corresponderia à ordem do "material". Sabemos que essa própria dicotomia resulta em um modo de produzir essa relação. Além da dicotomia, também observamos que o resultado dessa conversa produz, em muitos casos, a tendência à subordinação de um domínio de conhecimento sobre o outro: ora na direção de um reducionismo mecânico, onde os fenômenos psíquicos, tais como a cognição e as emoções seriam passíveis de ser totalmente traduzidos em termos de neurônios, neurotransmissores, código genético, substâncias químicas; ora na direção de uma transcendência a todo modo de operar orgânico. Pensamos que vale a pena insistir em um outro modo de encontro entre a Psicologia e a Biologia para os propósitos de nossa reflexão. Maturana e Varela (1997), ao definir a vida como uma organização autopoiética, deslocam o modo de perguntar. Propóem uma forma de explicar a relação entre a dinâmica estrutural do ser vivo e suas ações como radicalmente acopladas ao modo como se organiza a vida. A pergunta que fazem não é mais o que é a vida, mas, como ela funciona para dar origem aos modos cognitivos e emocionais 
observáveis. Perguntam que tipo de realização, de experiência do viver constitui o conhecimento, o amor, a competição, a não-aprendizagem? Em nosso caso interessaria indagar que tipo de experiência universitária produz esses modos de ser observador, de pesquisar, de separar a pesquisa, o ensino e a extensão?

Para Maturana existe uma diferença quando um observador pergunta o porquê de um fenômeno ou quando pergunta como opera esse fenômeno. Na primeira posição, o observador busca uma justificação, um fundamento ou princípio explicativo que dê conta do fenômeno, constituindo uma relação de causalidade geralmente linear. Assim, se pergunto por que uma criança não aprende na escola, as justificativas muitas vezes produzem uma listagem de "causas" que provocariam essa "consequiência" individual de não aprender. Dentre a lista de "causas" mais cotadas pelos professores estão: causas biológicas, emocionais e de imaturidade (Moysés, 2001). Ao contrário, se perguntamos que tipo de experiência se produz na escola que é capaz de gerar crianças que não aprendem?, buscamos construir um mecanismo gerativo que ao ser colocado em funcionamento produz o fenômeno que pretendemos explicar. Assim, precisamos não de uma lista de possíveis causas e sua probabilidade de causalidade, mas compreender como se vive em uma escola, como as relaçôes se instituem, como se organiza uma experiência vital que constrói modos de viver, sentir, pensar de tal ou qual tipo. Aqui não interessa uma causalidade linear, mas uma causalidade em anel, ou seja, compreender um sistema de vida, seus múltiplos e heterogêneos modos de constituição e a recorrência de sua produção.

No caso de nosso debate específico, o do pesquisar na universidade como uma atividade quase desconectada do ensino e da extensão, cabe investigar os tipos de experiências que são passíveis de ser vividas no contexto universitário em relação ao pesquisar, que potencialmente poderiam produzir a fenomenologia que diagnosticamos. De acordo com Maturana (2001), um observador-cientista, leia-se pesquisador, resulta de um certo modo de (viver), ou melhor, de perguntar-se sobre o viver, não podendo produzir-se em um metaponto-de-vista independente desse mesmo processo de perguntarse. Observar e explicar são produtos de percursos vividos em distin- 
Maraschin, C

"Pesquisar e intervir"

tos domínios cognitivos. Resultam da convivência em uma comunidade de observadores (nos cursos acadêmicos, nos encontros científicos, nos grupos de pesquisa, na rede intertextual de divulgação acadêmica, na intermitente avaliação entre os pares). Se o domínio de uma ciência pode ser considerado como uma rede de conversações explicativas, essa rede não se produz em uma transcendência da vida do observador e da contingência de ações nas quais ele próprio se constitui, como pesquisador entre outros pesquisadores. A formação de um pesquisador ou de um profissional decorre de uma co-deriva estrutural, mais ou menos consciente, advinda na participação nessa mesma rede.

O explicar - seja ele produzido no domínio científico ou no da vida cotidiana - para os autores, busca produzir na linguagem uma reformulação da experiência que conta como possibilidade as congruências da própria experiência. Condição que funciona, ao mesmo tempo, como um limite e possibilidade. Nesta formulação, o critério de validação de uma explicação não faz apelo a uma realidade exterior independente dos modos de explicar. As explicaçôes científicas podem ser assim consideradas, pois ativam mecanismos de controle - evitando produções fantásticas e/ou reducionistas através da instituição de critérios de validação construídos de acordo com as congruências e contingências de vida da rede de conversações da qual o observador participa. Por isso mesmo, as explicações são sempre reformuláveis. As características de imanência, de auto-recorrência e interpessoalidade das explicações podem ser tomadas como desconsertantes para os que definem a validade do resultado da pesquisa com referência a uma exterioridade independente do pesquisador. A explicação, afirma Maturana (2001), não necessita utilizar como critério de validação a referência a algo externo à própria rede de conversações que constitui as congruências do domínio de conhecimento. Cada domínio de conhecimento é um domínio de coordenações de açôes na praxis do viver em uma comunidade de observadores-pesquisadores. Deste modo, a proposição cognitiva "eu sei" deve ser entendida como resultante de uma operação em um domínio de coordenaçóes de ações no qual o observador e a observadora se encontram. 
Psicologia \& Sociedade; 16 (1): 98-107; Número Especial 2004

Existimos como pesquisadores (ou nos termos do autor, como observadores) em comunidades constituídas por sistemas de coordenações de ações na linguagem, como redes de conversações possibilitadas por determinadas emoçóes. E é dessa maneira - imanente, auto-recorrente, interpessoal e emocional - que existe a possibilidade da criação da autoria e da implicação ética no pesquisar.

Mas como se constitui um domínio explicativo? Ou podemos ainda dizer, um domínio de exercício de autoria? Maturana (2001) propõe que um domínio explicativo é constituído pelas coerências das experiências compartilhadas por aqueles que as aceitam como válidas no escutar. Domínio ou território significa um âmbito procedural, operatório no qual certos procedimentos têm validade para determinada comunidade de observadores. Nesse sentido, autoria passa a ser função de uma operatividade reflexiva dentro de um certo domínio coletivo de ações que pode ter como efeito à produção de uma diferença nessa rede de conversaçóes. Tal como a condição de observador, o autor só existe na imanência, na recorrência, na interpessoalidade e na emocionalidade. Muito distante da idéia de auto-fundacionismo e próxima a idéia de autopoiésis.

O explicar também se produz em um enlace com o tempo. Maturana constrói uma interessante argumentação para nos fazer pensar sobre a impossibilidade de um explicar na experiência atual, mas que todo o explicar surge também a posteriori, como uma outra experiência que reformula a anterior. Nos diz Maturana que no momento em que vivo uma experiência não possuo critérios de distinção entre percepção e ilusão. Assim, ao andarmos por uma rua deserta uma sombra ao longe pode ser vivida como perigosa. No instante da experiência de perigo não tenho critérios para distinguir se a realidade da sensação de perigo é válida ou não. Essa distinção só é feita a posteriori, quando essa experiência é reconfigurada em um domínio explicativo dado pelas coerências desse experienciar com outros experenciares, ou seja, somente quando posso distinguir essa sombra a partir das coerências com experiências anteriores é que posso julgar se a experiência real do sentimento de perigo é válida ou não. $\mathrm{O}$ autor segue sua argumentação: se aceitarmos que na experiência não podemos distinguir entre percepção e ilusão, isso demonstra que não temos acesso direto a uma realidade inde- 
Maraschin, C.

"Pesquisar e intervir"

pendente. A explicação se produz em um segundo tempo, pelas coerências operacionais constituídas pelo viver compartilhado em determinado domínio explicativo. As explicações são, portanto, estruturalmente determinadas por nossos modos de viver. O observar e o observador, o explicar e o autor se distinguem no operar desse mecanismo.

\section{PESQUISAR COMO AÇÃO ÉTICA E CRIATIVA}

Se aceitarmos que o pesquisar é produto e ao mesmo tempo produz, recursivamente, um domínio de conhecimento, no qual, autorias singulares podem ter existência; e que a validação da explicação não necessita de um referente externo às próprias coordenações de coordenações consensuais do operar do domínio cognitivo, então, participar desse processo constitutivo nos faz também responsáveis pelas subjetividades-observadores que nos tornamos, como também pelas objetividades-consensuais que produzimos. A implicação ética se institui ao perguntar-se pelo modo como nos constituímos como observadores, a resposta envolve a explicitação dos mecanismos capazes de gerar conhecimentos valorados como válidos para essa comunidade (conhecer), também envolve a produção de objetos cognoscíveis (multiversos). Aqui é interessante pensar na autoria tanto em sua dimensão criativa quanto ética. Se a atividade do explicar não é a de "desvelar" um segredo natural ou essencial, mas sim a de construir um critério explicativo aceitável em uma comunidade de observadores, como propóe Maturana (1997), então essa atividade explicativa implica em escolhas, conscientes ou não, e essas mesmas escolhas podem ser passíveis tanto de decisões estéticas quanto éticas. Toda autoria é, ao mesmo tempo, exercício de autonomia e de implicação, de resposabilidade pelo que se cria.

Uma das implicações dessa concepção de autoria é que se em nosso modo de viver em explicaçôes podemos produzir diferentes territórios existenciais, embora todos sejam legítimos - no sentido de realidades existenciais a partir de coerências próprias - não são, porém, todos desejáveis, no sentido de promoção da vida, de expansão de modos interativos, de salvaguarda da diversidade, de enfim, 
Psicologia \& Sociedade; 16 (1): 98-107; Número Especial 2004

projetos coletivos emancipatórios e democráticos. E aqui talvez encontremos um dos grandes desafios à avaliação das produções universitárias, já que tendemos a avaliar como válidas somente as "pequisaçôes" que pertencem ao mesmo domínio de conhecimento no qual fomos constituídos como observadores.

Todo pesquisar é uma intervenção, criação de sujeitos, objetos, conhecimentos, de territórios de vida. Mas gostaria de pontuar um pouco mais a relação pesquisa-intervenção talvez como um daqueles necessários laços de conexão na dinâmica universitária e profissional. Como pesquisadores do campo das ciências humanas, nosso perguntar indaga sobre os modos de viver, de existir, de sentir, de pensar próprios de nossa ou de outras comunidades de sujeitos. $\mathrm{O}$ próprio fato de perguntar produz, ao mesmo tempo, tanto no observador quanto nos observados, possibilidades de auto-produção, de autoria. Nossos "objetos de pesquisa" também são observadores ativos, produzem outros sentidos ao se encontrarem com o pesquisador, participam de redes de conversaçôes que podem ser transformadas a partir de novas conexões, novos encontros.

O pesquisar torna-se ele mesmo inovação, no momento que constitui um outro domínio de ação (outra comunidade de observadores), pautadas no explicar, no qual é afirmada a possibilidade de conhecer, compreender e transformar, ou não, as congruências que configuram os próprios modos de explicar o viver posto em questão. Nesta posição é que podemos pensar a questão da autoria, não somente como produção subjetiva do pesquisador como também nos sujeitos pesquisados. E aqui o próprio método é uma intervenção, no sentido de propor a possibilidade do exercício da posição de observador, de autoria.

Podemos tomar como exemplo o pesquisar a partir do encontro entre ferramentas tecnológicas digitais e algumas práticas educacionais. A inovação não é a presença das ferramentas em si, mas sim dos modos como esse encontro reorganiza as explicações, ou a rede de coerências, a rede de conversações anteriores. Perguntar pelas transformações de um domínio de ações de aprendizagem que se

1 Uso as palavras pesquisa e ações de forma acoplada para diferenciar da tradição da pesquisa-ação. 
Maraschin, C

"Pesquisar e intervir"

encontra com ferramentas tecnológicas diferenciadas da tecnologia ali existente, já é uma intervenção pois é capaz de produzir essa condição de observação não somente no sujeito-pesquisador mas também no sujeito-pesquisado (participantes desse ambiente de aprendizagem). O pesquisar pode se constituir em uma tecnologia de conhecimento capaz de produzir posições subjetivas de invenção, oferecendo outras possibilidades de existência, de constituição de outros enredos (já que explicar é uma contínua reformulação da experiência com a experiência).

Certamente a proposição anterior não implica a afirmação de que alunos e professores poderão, por participar de uma pesquisa, se transformar necessariamente em pesquisadores. O que afirmamos é que o pesquisar pode potencializar a experimentação de diferentes acoplamentos tecnológicos, para além de seu caráter utilitário ou instrumental (como, por exemplo, a questão recorrente de como a tecnologia ajudará os alunos a aprender melhor...). Essa experimentação, ao demandar uma explicação pelo modo como os sujeitos vivem o acoplamento, poderá possibilitar uma transposição desses limites, ressignificando a experiência anterior (cfe. AXT e MARASCHIN, 1997 e 1998). Ou seja, nosso "objeto" também pode conhecer, criar e subjetivar.

A condição construtiva do próprio "sujeito da pesquisa" não envolve apenas uma questão técnica do pesquisar, mas também e novamente, da implicação - ético-política - desta mesma ação. Outro laço necessário! Qual a proposição, o desejo que produz a aposta no pesquisar? Vou buscar o consentimento do sujeito de minha pesquisa porque desejo que possa se constituir uma co-responsabilidade para participar de uma pesquisa-experiência-explicação constitutiva de um possível novo enredo? Ou porque esse mecanismo garante uma "salva-guarda", uma proteção individual ao pesquisado, ou, ainda, em maior grau, ao pesquisador?

O percurso argumentativo explicitado, auxiliado por alguns conceitos da Biologia do Conhecer, pode tornar explícito como o pesquisar se produz em uma rede de conversações que também institui, no mesmo ato, a intervenção e a co-responsabilidade ética de autorias de si e do mundo. Poder explicitar todas essas repercussóes decorrentes do pesquisar pode recriar laços entre ensino-pesquisaextensão em nossos domínios universitários de convivência. 
Psicologia \& Sociedade; 16 (1): 98-107; Número Especial 2004

\section{REFERÊNCIAS}

AXT, Margarete e MARASCHIN, Cleci. Prática pedagógica pensada na indissociabilidade conhecimento-subjetividade. Educação e Realidade, Porto Alegre, v. 22 n. 1, 1997.

AXT, Margarete e MARASCHIN, Cleci. Narrativas auto-avaliativas: categorias operativas autopoiéticas de conhecimento. Livro de resumos da Anpepp, Gramado/RS, maio 1998.

MATURANA, H. R. Cognição, ciência e vida cotidiana. Org. Cristina Magro e Victor Paredes. Belo Horizonte: Ed. UFMG, 2001.

MOYSÉS, Maria Aparecida Affonso. A institucionalização invisivel: crianças que não-aprendem-na-escola. Campinas: Mercado de Letras; São Paulo: Fapesp, 2001.

Cleci Maraschin é Professora do Pós-Graduação em Psicologia Social e Institucional da UFRGS. $O$ endereço eletrônico da autora é: clecimar@orion.ufrgs.br

Cleci Maraschin

Pesquisar e intervir

Recebido: 20/11/2003

$1^{a}$ revisão: $5 / 3 / 2004$

Aceite final: 12/4/2004 